\title{
Isthmocele, an underecognised cause of secondary infertility and pregnancy outcome after endoscopic repair: a case report
}

\author{
Aradhana K. Dawar ${ }^{1 *}$, Akshay K. Nadkarni ${ }^{2}$, Tuleeka Sethi ${ }^{3}$
}

\author{
${ }^{1}$ Department of Reproductive Medicine, Milann Fertility, E580, Greater Kailash 2, Delhi, India \\ ${ }^{2}$ Department of Endoscopy and Oncology, 21st Century Hospitals, Vapi, Gujarat, India \\ ${ }^{3}$ Department of Obstetrics and Gynecology, SCI Hospital, Delhi, India
}

Received: 07 February 2021

Accepted: 09 March 2021

\section{*Correspondence:}

Dr. Aradhana K. Dawar,

E-mail ID: draradhanakalra@gmail.com

Copyright: ( $\subseteq$ the author(s), publisher and licensee Medip Academy. This is an open-access article distributed under the terms of the Creative Commons Attribution Non-Commercial License, which permits unrestricted non-commercial use, distribution, and reproduction in any medium, provided the original work is properly cited.

\begin{abstract}
Isthmocele is a niche at the area of previous cesarean scar. 38 year old lady presented with secondary infertility and decreased ovarian reserve for IVF with previous caesarean 8 years back. Isthmocele confirmed on 3D USG. Hysteroscopic guided laparoscopic repair done after initial failed ET without surgery. Postsurgical observations were increased myometrial thickness, improvement of abnormal bleeding, pain and successful conception and delivery with frozen embryo transfer. Isthmocele is an iatrogenic pathology associated with obstetric and gynecological complications. It's an under recognised cause of secondary infertility. Etiology could be poor tissue healing or surgical techniques favouring niche formation. It's imperative to address to its causes during caesarean section to prevent it. Diagnosis is mostly missed. Given the absence of a clearly defined surgical method in literature, choosing the proper approach to treating isthmocele can be arduous. Laparoscopy provides a minimally invasive procedure in women with this defect with secondary infertility and improves the chances of conception.
\end{abstract}

Keywords: Caesarean scar defect, Isthmocele, Hysteroscopy, Laparoscopy, Myometrial thickness

\section{INTRODUCTION}

With the increasing evaluation by diagnostic hysteroscopy and an increase in rate of cesarean sections there has been an emerging trend towards diagnosis of isthmocele. It's nothing but a defect in the previous cesarean scar which appears like a niche or a pouch in the anterior wall of the uterus at the area of previous scar on ultrasound and accumulates menstrual blood which floats in the endometrial canal.

It has been 40 years since Stewart et al in 1985 first reported the relationship of abnormal bleeding with caesarean section. ${ }^{1}$ Isthmocele still remains a markedly under recognised cause of secondary infertility. The worldwide incidence is $6.2 \%$ to $36 \%$, with an average rate of $21.1 \% .^{2}$
The symptoms due to isthmocele are post menstrual spotting, chronic pelvic pain, dyspareunia, secondary infertility and obstetric complications like caesarean scar ectopic pregnancy, malplacentations, scar dehiscence. . $^{3,4}$ All these may be collectively called caesarean scar syndrome. Presence of this niche may also pose difficulty during IUCD insertion, uterine evacuation and hysteroscopy.

\section{CASE REPORT}

A 38-year-old lady P1L1, previous LSCS 8 years back, presented with secondary infertility and decreased ovarian reserve for IVF. USG evaluation revealed fluid in the endometrial cavity and a niche at the area of previous scar. Detailed history revealed she had post menstrual spotting for 5 to 6 days since last caesarean section. She had undergone a hysteroscopy and laparoscopy 3 years 
back for infertility but it mentioned nothing significant. On the day of ovum pick up, significant fluid was seen in the cavity. It was aspirated under ultrasound guidance and was found to be altered blood. Isthmocele confirmed by $2 \mathrm{D}$ and 3D USG with very thin myometrium behind the niche (Figure 1a). Frozen embryo transfer was done in a down regulated cycle after aspirating the fluid in the same cycle and 2 grade AB blastocysts were transferred. This transfer did not yield a pregnancy.

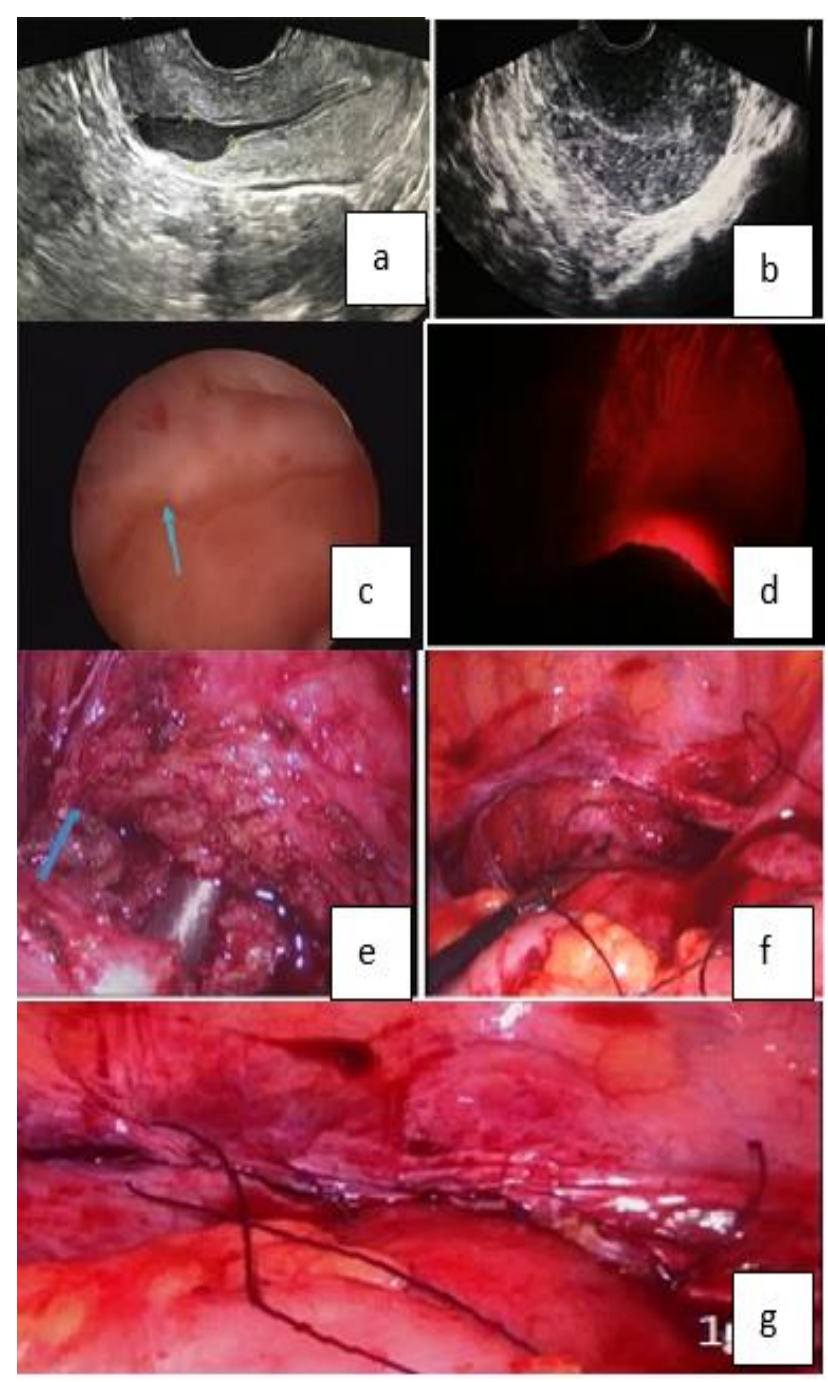

Figure 1: (a) Transvaginal sonographic image showing isthmocele in the midsagittal view; (b) after isthmocele repair; (c) hysteroscopic image showing isthmocele; (d) laparoscopic image showing maximum transillumination at the thinnest area; (e) thickness of the pathological area resected, shown with a dilator in the cervix; (f) closure of first layer with intermittent sutures; and (g) two layered closure of the defect with bladder flap.

After proper counselling hysteroscopic guided laparoscopic repair was done. Hysteroscopy revealed a crater just above the internal os with accumulated blood (Figure 1c). Site of the scar can be pointed by scissors hysteroscopically after pushing the bladder down or can be seen on transillumination during laparoscopy (Figure 1d). The margins of previous scar were excised and sutured in two layers with polyglactin number 1 . Ultrasound in the subsequent months after surgery revealed disappeared niche with no fluid in the cavity (Figure 1b).

Frozen embryo transfer was done after 3 months, two day 5 embryos grading $4 \mathrm{AB}$ and $4 \mathrm{BA}$ transferred.

Patient conceived in this attempt. Antenatal care was routine. Scar thickness was followed in the third trimester and she underwent an elective caesarean delivering a healthy girl child at 37 weeks. Per operative during the caesarean section, the scar was intact and there were minimal peritoneal adhesions. Patient's written and informed consent is taken prior to submission.

\section{DISCUSSION}

Infertility has remained a major challenge since decades. The advancement in the field of reproductive medicine has also invariably contributed to an upsurge in the incidence of caesarean sections. The WHO, global survey indicates that overall caesarean rates have increased over time in all countries except Japan from 26.4 to $31.2 \%$ in a multicountry survey $(\mathrm{p}=0.003) .{ }^{5}$ The increasing cases of isthmocele being heard of in this decade despite their first description in 1985 by Stewart et al is attributed to the surge in the cesarean section rates. All women who have isthmocele may not be symptomatic and not all require treatment. Isthmocele or the niche were defined as indentations of the myometrium of at least $2 \mathrm{~mm} .{ }^{5}$ Large niches occur less frequently, with an incidence varying from 11 to $45 \%$ dependent on the definition used (a depth of at least 50 or $80 \%$ of the anterior myometrium, or the remaining myometrial thickness $\leq 2.2 \mathrm{~mm}$ when evaluated by TVS and $\leq 2.5 \mathrm{~mm}$ when evaluated by sonohysterography). ${ }^{6}$

The plausible cause of infertility could be blood in the endometrial canal and cervix during ovulation hindering sperm penetration and embryo implantation.

While we know caesarean is a lifesaving procedure especially in true cases of fetal distress, placenta praevia, malpresentations, many who undergo caesarean may also do well without it. So, it's important to re-evaluate the indications and reduce the number of caesareans. Along with this we need to understand the etiology behind niche development to prevent its formation after caesarean section.

Hypothesis for niche development is poor wound healing and related angiogenesis, low (cervical) location of the uterine incision during a caesarean section, single layer closure of the uterus or incomplete closure with endometrial sparing technique. Locking of the first layer, is associated with decreased myometrial thickness, although the rate of scar dehiscence in subsequent cesarean remains unchanged. $^{7}$ Risk of increased 
adhesions due to certain surgical practices (i.e. nonclosure of peritoneum, inadequate haemostasis, applied sutures, use of adhesion barriers). ${ }^{8}$ It's also observed that isthmocele is more common in retroflexed uteri. ${ }^{5}$ Counteracting forces in a retroflexed uterus along with retractions due to adhesions at the bladder base especially in cases where bladder flap is created and raw peritoneum left unsutured may result in poor wound healing.

The lower location of the scar is evident in our case in the ultrasound image (Figure 1a). The diagnosis is difficult and its missed most of the times. Our patient had also undergone laparoscopy earlier but the diagnosis could not be made. Diagnosis is by hysterosalpingography, 2D or 3D ultrasonography, saline or gel infusion sonography or during hysteroscopy. ${ }^{9}$ Treatment for secondary infertility with symptomatic isthmocele or persistent fluid or large defects is surgical. Approach can be vaginal, hysteroscopic or hysteroscopic guided laparoscopic resection. Vaginal isthmoplasty is performed by entering the vesicocervical space, the defect is identified, excised and the opening sutured. ${ }^{10}$ Compared to hysteroscopic approach, vaginal repair was associated with a longer surgical time and greater blood loss. ${ }^{11}$ While only hysteroscopic correction may be less invasive, it primarily shaves off the margins of the niche or crater and aims at hindering fluid accumulation. This way it may improve post menstrual spotting or fertility but the scar still remains weak with the risk of uterine perforation. To avoid this cut off of atleast $2 \mathrm{~mm}$ overlying myometrium is suggested. ${ }^{12}$

Laparoscopic resection and resuturing the weakened scar aim at strengthening the scar and may ameliorate the chances of scar dehiscence, scar ectopic and fluid accumulation. Laparoscopic repair led to uterine bleeding improvement in $86 \%$ of cases and a pregnancy rate of $86 \% .^{13}$ So, the surgery should be limited to those cases who are symptomatic, have persistent fluid in the endometrial canal and there is marked thinning of the myometrium behind the niche.

\section{CONCLUSION}

Isthmocele is an iatrogenic pathology. A patient with vaginal delivery will never have an isthmocele. It's important to critically analyse our caesarean rates in obstetric practice. It is imperative to understand the etiology and adopt preventive measures during cesarean to reduce its occurrence. Given the absence of a clearly defined surgical method in the literature, choosing the proper approach to treating isthmocele can be arduous. Laparoscopy provides a minimally invasive procedure in women with previous caesarean scar defects and improves the chances of conception.

Funding: No funding sources Conflict of interest: None declared

Ethical approval: Not Required

\section{REFERENCES}

1. Stewart KS, Evans TW. Recurrent bleeding from the lower segment scar-a late complication of Caesarean section. Br J Obstet Gynaecol 1975;82:682-6.

2. Nezhat CM, Grace L, Soliemannjad R, Razavi GM, Nezhat A. Cesarean Scar Defect: What Is It And How Should It Be Treated? Obg Management. 2016;28(4):32-53.

3. Vervoort AJ, Uittenbogaard LB, Hehenkamp WJK, Brolmann HAM, Mol BWJ, Huirne JAF. Why do niches develop in caesarean uterine scars? Hypothesis on the aetiology of niche development. Hum Reprod. 2015;30(12):2695-702.

4. Florio P, Filippeschi M, Moncinia I, Marrac E, Franchinid M, Gubbini G. Hysteroscopic treatment of the caesarean induced isthmocele in restoring infertility. Curr Opin Obstet Gynecol 2012;24(3):180-6.

5. Bij de Vaate AJ, Brolmann HA, van der Voet LF, van der Slikke JW, Veersema S, Huirne JA. Ultrasound evaluation of the Cesarean scar: relation between a niche and postmenstrual spotting. Ultrasound Obstet Gynecol 2011;37:93 -9.

6. Van der Voet LF, Bij de Vaate AM, Veersema S, Brolmann HA, Huirne JA. Long-term complications of caesarean section. The niche in the scar: a prospective cohort study on niche prevalence and its relation to abnormal uterine bleeding. BJOG. 2014;121:236 -244.

7. Yasmin S, Sadaf J, Fatima N. Impact of methods for uterine incision closure on repeat caesarean section scar of lower uterine segment. J Coll Physicians Surg Pak. 2011;21:522-6.

8. A.J.M.W. Vervoort, L.B. Uittenbogaard, W.J.K. Hehenkamp, H.A.M. Brolmann, B.W.J. Mol, and J.A.F. Huirne. Why do niches develop in Caesarean uterine scars? Hypotheses on the aetiology of niche development. Human Reproduction. 2015;30:26952702.

9. Borges LM, Scapinelli A, de Baptista Depes D, Lippi UG, Coelho Lopes RG. Findings in patients with postmenstrual spotting with prior cesarean section. Ultrasound Obstet Gynecol. 2010;17:361-4.

10. Zhang Y. A comparative study of transvaginal repair and laparoscopic repair in the management of patients with previous caesarean scar defect. J Minim Invasive Gynecol. 2016;23:535-41.

11. Xie H, Wu Y, Yu F, He M, Cao M, Yao S. A comparison of vaginal surgery and operative hysteroscopy for the treatment of caesarean induces isthmocele: a retrospective review. Gynecol Obstet Invest. 2014;77:78-85.

12. Chang Y, Tsai EM, Long CY, Lee CL, Kay N. Resectoscopic treatment combined with sonohysterographic evaluation of women with post menstrual bleeding as a result of previous cesarean delivery scar defects. Am J Obstet Gynecol. 2009;200(4):3701-4. 
13. Tulandi T, Cohen A. Emerging Manifestations of Cesarean Scar Defect in Reproductive-aged Women. J Minim Invasive Gynecol. 2016;23:893-902.
Cite this article as: Dawar AK, Nadkarni AK, Sethi T. Isthmocele, an underecognised cause of secondary infertility and pregnancy outcome after endoscopic repair: a case report. Int J Reprod Contracept Obstet Gynecol 2021;10:1717-20. 